Available online on 15.02.2020 at http://jddtonline.info
Open Access to Pharmaceutical and Medical Research
unrestricted non-commercial use, provided the original work is properly cited

Open Access

Research Article

\title{
Investigation of Drug Distribution Process and Pharmacy Practices on Model Pharmacy in Dhaka City, Bangladesh
}

\author{
Md. Mominur Rahman*, Shafana Sherin, Ahasanul Mahabub Jubayer, Fahadul Islam, Nusrat Jahan, Md. \\ Saidur Rahaman, Moriam Akter Sumi , Khandaker Sanjida Akter, Mukhles, Firoza Rahman, Md Farid \\ Hossain, Md. Faysal
}

Department of Pharmacy, Faculty of Allied Health Sciences, Daffodil International University, Dhaka-1207, Bangladesh

\begin{abstract}
Objectives: In Bangladesh, Drug distribution process is very important cause of our increasing economic and development. In the recent days Model pharmacy has become an important theme of study for the student in pharmacy. In Bangladesh the introduction of the model pharmacy practice likes other skilled and semi-skilled health professionals will certainly improve primary health care system. The aim of the study was to develop a strategy to improve the overall services of model pharmacy in Bangladesh.
\end{abstract}

Methodology: A total of 20 model pharmacies were the study subject. The study cover the model pharmacy located in Dhaka city, where each pharmacy was accounted through a questioner on random basis. The form includes their facilities, management system, drug distribution process and counseling system.

Results: Study showed that, out of 20 Pharmacists, 95\% of them used Software tools for their drug dispensing system. There was a helpline system for individual, online order within a short time of delivery system, discount system and membership card. The most important significant factors are counseling by "A grade" pharmacists, patient database system, affordable price and quality of medicine.

Conclusions: If we improve those model pharmacies and if the aim is successful, then it will be spread across Bangladesh and model pharmacy will be established gradually with digitalization.

Keyword: Model pharmacy, Bangladesh, Dhaka city, Pharmacist, Drug distribution process

Article Info: Received 19 Nov 2019; Review Completed 21 Jan 2020; Accepted 27 Jan 2020; Available online 15 Feb 2020

\section{Cite this article as:}

Rahman MM, Sherin S, Jubayer AM, Islam F, Jahan N, Rahaman MS, Sumi MA, Akter KS, Mukhles, Rahman F, Hossain MF, Faysal M, Investigation of Drug Distribution Process and Pharmacy Practices on Model Pharmacy in Dhaka City, Bangladesh, Journal of Drug Delivery and Therapeutics. 2020; 10(1-s):165-173 http://dx.doi.org/10.22270/jddt.v10i1s.3890

*Address for Correspondence:

Md. Mominur Rahman, Department of Pharmacy, Faculty of Allied Health Sciences, Daffodil International University, Dhaka-1207, Bangladesh

\section{Introduction}

Model pharmacy means developing; implementing \& conforming uniforms standards for the purpose of protecting the public health, pharmacy services are provided in a range of seating hospitals, community, pharmacy care, industry, and academia. [1] Model pharmacy is a community-based pharmacy where responsibilities include: checking and dispensing of prescription drugs, providing advice on drug selection and usage to doctors and other health professionals and counseling patients in health promotion, disease prevention and the proper use of medicines. Community pharmacists are playing an important role in any country as they take responsibilities of patients' medicine related needs to assure a better healthcare. Most community pharmacists in the country still can hardly offer patientoriented service. The role of pharmacists in the community as well as their medicine management may change in the pattern of the rapid growth of domestic medicine use and national healthcare expenditure. In most countries regulatory authorities govern how dispensaries may operate, with specific requirements for storage conditions, equipment and record keeping. For these purpose Bangladesh government would be established this service and the drug control agency of government is working for stopping fake drug sales in Bangladesh. Last 22 December 2016, 33 model pharmacies have been established such as Lazz pharma at Dhanmondi, biomate at green road, safabi pharma,islam pharma at gulshan-2,al-madina at gulshan1,tamanna pharmacies and prescription aid at banani and others in sylhet. Gradually this service has been reached in all districts that health ministry has informed. Model pharmacy is one of the greatest achievements of present government in Bangladesh. On the other it creates the new job opportunity for graduate pharmacists and non- 
graduate pharmacists. The new name of service for health is model pharmacy. In this model pharmacy should have agrade, b-grade and two c- grade registered pharmacists besides 600 squares area and proper temperature for keeping medicine. The roof of this building should have proper distance and the temperature of the freeze should be right beside the prescription service desk. On the other hand this model pharmacy should have separate corner for pharmaceutical products and none pharmaceutical products and instruments. Model pharmacies will be allowed to stock and sell all non-prescription (OTC) medicine registered by dgda. It shall be maintained a record of all medicine dispensed in a register approved by dgda .for each prescription dispensed a record shall be made as follows:

- Serial number of entry,

- Date of sale,

- Name/code number and address of the prescriber,

- Name of the patient and condition for which the prescription was written.

- Name of the drug preparation and the quantity of suppliant.

The model pharmacy should maintain automated system to preserve all suppliers' receipts and invoice for prescription and non-prescription medicines and store all hard copies of the same supplier invoices and receipts on the premises for non-less than two years. A purchase record book shall be kept, which shall minimally include.

DGDA has successfully completed all the phase-1 activities to initiate model pharmacy. The secretary of the ministry of health and family welfare has approved the classification of all private retail drug outlets into two types, pharmacy and medicine shop. The approved standards will be the ultimate guide for implementing and evaluating the Bangladesh pharmacy model in target districts during phase- 2 .

\section{Objectives of Model Pharmacy}

- To reinforce regulations in the model pharmacy business.

- To achieve service uniformity among pharmacies and medicine shops.

- To maximize patient care with minimize health hazard

- To maintain drug preserve environment properly

- Gain knowledge about different medicine

- $\quad$ Build up good relationship with patient.[2]

Model Drug Outlet Operations in Bangladesh [3, 4]

All drug outlets should operate on the principle of making the safety and welfare of customers the prime concern. All pharmaceutical service providers are required to operate in a secure and safe environment in accordance with legal and professional requirements and present an image that enhances pharmaceutical services.

Model Pharmacy (Level I): This level of service will be provided, managed, or supervised by an A grade pharmacist who is present on the premises. B or C grade pharmaceutical personnel may assist with dispensing under the supervision of the A grade pharmacist.
Model Medicine Shop (Level II): This level of service will be carried out, at a minimum, by a person with $\mathrm{C}$ grade qualification.

\section{The Standards For Model Pharmacies And Model Medicine Shops Follow These Principles:}

-The governance arrangements are made with the aim of safeguarding the health, safety and well-being of patients and the public.

- The personnel are empowered and competent to provide desired services to safe guard the health, safety, and wellbeing of patients and the public.

-The environment and condition of premises from which pharmaceutical services are provided and any associated premises, regardless of level of service, safeguard the health, safety, and well-being of patients and the public.

-The way in which pharmaceutical services are provided and medicines and medical devices are managed and delivered safeguards the health, safety, and well-being of patients and the public.

-The equipment, facilities, or utilities used during the provision of pharmaceutical service safeguard the health, safety, and well-being of the patient and the public

\section{Standards for Model pharmacies:}

These standards are for the establishment and operation of Model Pharmacies. The standards consider the skills and competencies of dispensers and the A grade pharmacists overseeing this service level, types of medicines to be sold, and the infrastructure of the physical premises.

Standards for Personnel [5, 6]

Personnel at every Model Pharmacy shall fulfill the following requirements.

\section{Owners}

Every Model Pharmacy owner must:

- Have a Bangladesh national ID.

- Have a tax identification number (TIN).

- $\quad$ Have a trade license.

- Take the Pharmacy Council of Bangladesh (PCB)approved business training course and pass the postcourse examination.

\section{Every Model Pharmacy Owner Shall:}

- Ensure that the Model Pharmacy staff has the appropriate skills, qualifications, and competencies for their role and for the tasks they carry out.

- Prominently display the Pharmacy accreditation certificate, dispenser registration certificate(s), and trade license.

- Prominently display the name of the pharmacist-incharge for the premises and his/her registration certificate in the professional service area.

- Notify the DGDA in writing within 30 days after the Model Pharmacy permanently closes; in so doing, the authority shall inspect the inventory and provide advice for proper disposal of medicines and other products.

- Notify the DGDA in writing within 30 days after the Model Pharmacy temporarily closes with the anticipated date of reopening, which should also be 
publicly displayed in front of the premises. Should a Model Pharmacy close for one year, it shall be considered a new applicant for accreditation.

- Notify DGDA in writing within seven days for any change in approved personnel including when a notice for termination of contract with pharmacistin-charge is issued.

- $\quad$ Report any thefts or unexplained losses of drugs or records immediately to the nearest police station and to DGDA.

Technical Personnel Responsible for Medicines Dispensing

All A, B, and C grade pharmaceutical personnel working in the Model Pharmacy must undergo a PCB-approved 30hour orientation (A and $\mathrm{B}$ grade) or 80 -hour dispensing training course ( $\mathrm{C}$ grade) and pass the related exam. Any secondary school certificate holder in science who undergoes the PCB-approved 80-hour dispenser training course and passes the training exam may also be registered as a $\mathrm{C}$ grade dispenser.

The technical personnel working in a Model Pharmacy shall comply with the following:

- Maintenance of a high standard of personal hygiene.

- Guidelines on dispensing, ethics and other issues related to the provision of pharmaceutical services.

- Completion of continuing education if required by the PCB.

- $\quad$ Code related to personal identification and dress.

\section{Supervision of Model Pharmacy}

- Every Model Pharmacy will be managed or supervised on-site by an A grade pharmacist registered by the PCB (pharmacist in-charge).

- Model Pharmacy dispensers must work under the onsite supervision of an A grade pharmacist (pharmacist in-charge).

- Non-pharmaceutical personnel employed by the Model Pharmacy can be on the premises, but shall not keep the business open without a pharmacist incharge on the premises.

Contract between Model Pharmacy Owner and Pharmacist-In-Charge

- $\quad$ Every owner and pharmacist-in-charge must sign a legally binding contract.

- The contract will describe the roles and responsibilities of each party including terms and conditions.

- A generic template contract will be provided by DGDA to be used by each Model Pharmacy.

\section{Standards for Premises}

\section{Premises}

Every Model Pharmacy premises must meet minimum requirements as follows:

- Be a permanent structure that is not at risk from floods.

- Have a roof and ceiling free from leakage.
- Provide adequate seating for customers waiting for service.

- Have surfaces/floors/walls with smooth finish that can be washed with disinfectants.

- Assure good hygiene inside and outside the premises.

- Have a source of potable water.

- Have space with dimensions of at least 300 square feet and a ceiling height of at least 8 feet.

- Have a source of electricity such as a direct connection to an electrical grid, generator, instant power supply, or solar panels.

- Have a sink with running water dedicated to support hand hygiene practices.

- Where a Model Pharmacy prepares extemporaneous products, the sink must have sufficient space for cleaning related equipment.

- The sink should not be used for disposal of mop water and other liquid wastes.

- $\quad$ The building must be constructed and maintained to minimize entry of animals, such as rodents and birds.

\section{Signage}

Pharmacies will have the following signage:

- A sign board with the name of the outlet, registration number, addresses, and officially approved logo (brand) for a Model Pharmacy in accordance with DGDA's Model Pharmacy branding guidelines.

- A "NO SMOKING" sign conspicuously placed to prohibit smoking on the premises.

- A sign indicating operating hours.

- Upon closure or relocation, or loss of accreditation status, all signage indicating that the premise was a Model Pharmacy must be removed immediately.

\section{Temperature Control}

- The Model Pharmacy should have adequate air conditioner(s) with a power back-up source (e.g., generator, instant power supply, solar panel), so that the ambient temperature does not exceed $30^{\circ} \mathrm{C}$.

- $\quad$ The Model Pharmacy must have a thermometer to monitor room temperature.

\section{Refrigerator}

- The Model Pharmacy must have, at minimum, one pharmacy-grade refrigerator that is large enough to store temperature-sensitive medicines.

- $\quad$ All refrigerators used to store medicines must be dedicated to the storage of pharmaceuticals only.

- $\quad$ Refrigerators used for storage of vaccines must comply with vaccine storage guidelines.

\section{Security}

- External walls should be of solid construction to ensure they cannot be breached.

- Measures need to be taken to prevent entry through the ceiling. The ceiling spaces above Model Pharmacies should be secured to ensure the crawl spaces cannot be accessed from adjoining areas. 
- Walls must reach the roof line or security grills must be installed to cordon off the ceiling space.

- $\quad$ External doors must have a solid core. Where this is not possible, a heavy gauge roller door or security grill may be used in addition to a lockable door.

- $\quad$ All external entry points, including windows and skylights, must be lockable with additional security grills or roller doors. High security glass, equivalent in strength to a security grill or roller door, will be accepted. External bollards should be considered if the Model Pharmacy is at high risk of ram raid.

- Model pharmacies must be protected by a back-tobase electronic alarm system or CCTV security cameras to cover, at a minimum, areas where scheduled medicines are stored.

- All medicinal products, associated records, and recording equipment should be stored on the Model Pharmacy premises only.

\section{Professional Services Area}

- $\quad$ The Model Pharmacy must have a clearly delineated and marked professional service area restricted to the provision of therapeutic goods and services.

- The professional service area should be distinguishable from other areas of the Model Pharmacy; customers should readily be able to locate the dispensing area.

- $\quad$ The area should be designed and located such that consumers are able to access the advice of the pharmacist or other qualified pharmaceutical personnel to assist in their safe and effective use of therapeutic goods.

- The professional service area contains the dispensary, counseling area, prescription drop off and collection points, and over-the-counter and prescription medicine storage areas. The professional service area must be free from information, products, and services that are not therapeutically related.

- $\quad$ Non-therapeutic items (e.g., toiletries, cosmetics) should not be displayed for sale within the professional area.

- No person other than a member 0! The Model Pharmacy staff is allowed behind the counter in the professional services area.

- $\quad$ The dispensary must have a dispensing counter with a clean and smooth surface.

\section{Dispensing [7]}

\section{Good Dispensing Practices}

- $\quad$ Every pharmacist-in-charge shall bear professional responsibility for the pharmaceutical products and services provided by him or her or any other pharmaceutical technical personnel under his or her supervision.

- Patients whose conditions cannot be handled by the Model Pharmacy personnel should be referred to the nearest health facility.

- The pharmacist-in-charge shall ensure that:

a. No damaged, counterfeit, substandard, or expired medicines are dispensed. b. Medicines dispensed are registered by the DGDA.

c. No physicians' samples are dispensed.

d. No medicines are dispensed directly to children less than 12 years of age.

e. Prescription-only medicines are only dispensed against a prescription.

f. The patient is dispensed with the full course of treatment and directed to complete the full course of treatment.

g. Tablets and capsules are dispensed using an appropriate tool, such as a counting tray. They should not be handled with bare hands.

h. Every drug is dispensed in accordance with the Model Pharmacy dispensing and training guidelines/standards and in accordance with the existing DGDA laws, ordinances, and rules.

\section{Counseling Patients}

The pharmacist-in-charge shall ensure that:

- $\quad$ The customer receives dosing instructions and drug information before he or she leaves the premises.

- The customer understands the information and advice given (including directions on the labels of dispensed products) well enough to ensure safe and effective use of the medicine.

- $\quad$ Customers are warned to keep medicines well out of reach of children.

- $\quad$ Customer privacy is protected during counseling conversations through the use of a separate area or by requiring other customers to stand behind a line that allows for confidential conversations with the dispenser.

\section{Dispensing Containers}

- $\quad$ All oral liquid preparations must be dispensed in their original re-closable containers unless the product is supplied by the manufacturer in bulk.

- All dispensing containers for medicinal products must protect the medicine(s) from moisture, light, physical stress, and contamination.

- $\quad$ Dispensing containers should be labeled either by writing on the container or by using an adhesive sticker.

\section{Required Dispensing Tools}

The following items must be available and in use in Model Pharmacies:

- $\quad$ Counting tray

- $\quad$ Spatula

- Measuring tools

- Mortar and pestle

- $\quad$ Scale for body weight measurement

\section{Labeling Dispensed Medicines}

- $\quad$ Labeling of dispensed medicines must be clear and legible and in the locally appropriate language or using pictographs. 
- Dispensed medicines must bear the necessary cautionary and advisory labels.

- The label on the container must indicate:

a. Name and address of the patient.

b. Name of medicine.

c. Directions for use, strength, dosage, and total quantity of the medicine supplied.

d. If the medicine is for external application, the words "For external use only" must appear on the label.

e. Expiry date.

\section{Storage of Medicines}

- Have a separate place within the professional area with no public access to keep approved prescription medicines, either in a separate room or on shelves with sliding glass or in a lockable cupboard or drawer.

- $\quad$ Have shelves with sliding glass to protect medicines from dust in dispensing area; arrange medicines alphabetically or according to therapeutic groups. Solid dosage forms to be separated from liquids and internal preparations to be separated from external preparations. All shelves with medicines shall be behind or under the dispensing counter. All pharmaceutical products held in inventory shall be stored in the manufacturer's original packaging and properly labeled with the manufacturer's original label and under the storage conditions that are specified by the manufacturer (e.g., refrigeration) until they are dispensed.

- Damaged or expired medicines shall be recorded, sealed, quarantined, and labeled with the statement in red ink "Expired/damaged medicines-Not for sale."

- No medicine should be stored on the floor or in passageways, toilets, or staff rest areas.

- Vaccines can be stocked if the Model Pharmacy is able to maintain cold chain standards.

- $\quad$ Over-the-counter (OTC) medicines may be stocked outside the professional service area, but must be stocked close enough to allow effective oversight by the pharmacist-in-charge or other qualified pharmaceutical personnel.

Hygiene [8]

- Any dispenser or other personnel should not be allowed to work if he or she is suffering from a contagious disease condition, such as scabies, tuberculosis, leprosy, etc.

- Use of bare hands for counting tablets and capsules is prohibited.

- Buildings and fixtures must be kept clean, tidy, and well maintained. All cleaning equipment must be maintained to support good hygiene and infection control.

- $\quad$ The Model Pharmacy shall maintain regular general cleaning schedules. Floors shall be cleaned daily and when necessary. Shelves shall be regularly cleaned to maintain dust-free environment.

- The dispensing area should be tidy and free of clutter.
- Model Pharmacy staff should not eat while working in the dispensing area. Staff should have a separate area for eating available to them.

- $\quad$ Toilets must not open directly into the dispensing area. Hand-washing facilities with running water, soap, and clean towels must be provided in toilet areas with a conspicuous notice displayed that instructs users to wash their hands.

- Toilet areas must not be used for storage or as a source of water for dispensing.

\section{Record Keeping and Documentation}

- A record of all medicines dispensed shall be maintained in a register approved by the DGDA.

- $\quad$ For each prescription dispensed, a record shall be made as follows:

a. Serial number of the entry.

b. Date of sale.

c. Name/code number and address of the prescriber.

d. Name of the patient and condition for which the prescription was written (if known).

e. Name of the drug or preparation and the quantity supplied.

- The Model Pharmacy should maintain automated (computerized) system to preserve all suppliers' receipts and invoices for prescription and nonprescription medicines AND store all hard copies of the same supplier invoices and receipts on the premises for not less than two years.

- A purchase record book shall be kept, which shall minimally include:

a. Name of supplier

b. Date of purchase

c. Name and quantity of the medicines

d. Manufacturer, batch number, and expiry date.

- A record for expired products must be maintained.

- $\quad$ Every Model Pharmacy must maintain a file for all correspondence received from DGDA, Ministry of Health and Family Welfare, or other regulatory authorities (e.g., drug recall notices).

- $\quad$ The Model Pharmacy must maintain a book to record all inspections.

- $\quad$ The Model Pharmacy must maintain DGDA-approved adverse drug reaction forms and adverse drug reactions must be reported to DGDA regularly.

\section{Disposal of Damaged/Expired Medicines}

The disposal of damaged/expired medicines must strictly follow existing rules and procedures as provided by DGDA and other competent authorities.

\section{Allowable Products and Services in Model Pharmacies}

\section{Prescription-only Medicines}

Model Pharmacies will be allowed to stock and sell all prescription-only medicines registered by DGDA.

\section{Non-prescription/Over-the-Counter (OTC) Medicines}

Model Pharmacies will be allowed to stock and sell all nonprescription/ OTC medicines registered by DGDA. 


\section{Medical Supplies and Devices}

- Model Pharmacies will be allowed to stock and sell medical supplies and devices other than medicines if they meet DGDA's established quality standards.

- All medical supplies and devices will be stocked separately from therapeutic products with distinct signage such as "Medical Supplies and Devices."

\section{Non-pharmaceutical Products}

- Model Pharmacies will be allowed to store and sell toiletries, cosmetics, and other hygiene and health promoting products.

- All non-pharmaceutical products will be stocked separately from therapeutic products with distinct signage such as "Non-pharmaceutical Products."

- DGDA approved/registered traditional /alternative medicines such as Ayurveda, Unani, or bio-chemic medicines may be stored and sold, but must be stocked separately from therapeutic products with distinct signage such as "Traditional/Alternative Medicines."

\section{Pricing of Pharmaceuticals}

Model Pharmacies must comply with the DGDA's recommended maximum retail price (MRP) for pharmaceutical products.

\section{Offenses and Penalties}

Model Pharmacies are subject to periodic regulatory inspection. Any person who violates any provision of these standards shall be liable upon conviction to a warning, fine, and/or imprisonment as specified under the existing acts, ordinance, and rules [4].

Daily Working Activity of a Pharmacist in Model Pharmacy:

1. To checking temperature

2. Maintain the design strategy

3. To check expire date of medicine

4. Check each patient's medication record every time he or she gets a new or refill prescription filled. This is the best way for a pharmacist to prevent potentially dangerous interactions between drugs.

5. Counseling with patients: This involves more than informing about adverse reactions and interactions with other medications, food, alcohol and other beverages like grapefruit juice. Counseling includes training patients how and when to take doses, following up with patients to see if medications are working, sharing tips on how to minimize side effects while maximizing benefits and listening to all of a patient's concerns.

\section{Layout of Patient Service}

The layout of this unit is important since it carries the good or bad impression about the pharmacy services the patients get. The unit should be provided with two windows, one for receiving the prescription and other for delivery. When the prescription is being compounded, the patients have to wait for some time. Hence waiting area should be provided. The waiting room should be clean and ventilated with sufficient number of comfortable seats. In the waiting room, general publications regarding pharmacy and medicines should be provided. It also includes the magazines and newspapers. The waiting period should be kept at minimum to avoid overcrowding. In the waiting room the wall posters should be displayed through which the patients can learn about the family planning methods and general hygiene. It will be very acceptable for patient.

\section{Role of Pharmacist in Prevention of Drug-Food Interaction:}

Pharmacists in every practice setting need to be vigilant in monitoring for potential drug-food interactions and advising patients regarding foods or beverages to avoid when taking certain medications. It is imperative for pharmacists to keep up to-date on potential drug-food interactions of medications, especially today's new drugs, so that they may counsel properly. In providing drug information to patients, pharmacists often discuss potential side effects and how the medication should be taken. It is important to provide information to patients on when to take their medications in relation to food intake. Consequences of drug-food interactions may include delayed, decreased or enhanced absorption of the drug. Food may also affect the bioavailability, metabolism and excretion of certain medications. The patient may experience an adverse side effect or toxicity or may not receive the full therapeutic benefit of the medication. The Joint Commission on the Accreditation of Healthcare Organizations (JCAHO) requires that a patient's medication profile include potential drug-food interactions, that the pharmacist call the prescriber whenever the potential for a medication-food interaction exists and document the communication and follow-up action on the prescription or order form, and that patients be given instructions and counseling regarding the potential for drug-food interactions before their hospital discharge. Elderly patients may be at a greater risk for drug-food interactions because they typically consume more medications for their chronic medical conditions. A study of drug-nutrient interactions in long-term care facilities found a significant relationship between the number of medications a resident consumed and the number of drug-nutrient interactions for which a resident was at risk [9-12].

\section{METHODS AND MATERIALS}

\section{Methods}

1. Number of Study center: 1

2. Number of Pharmacist: 20

3. Study site: Zigatola and Panthapath

4. Duration of study: 5 months

5. Study type: "Investigation of digital drug distribution process and pharmacy practice on model pharmacy in Dhaka city, Bangladesh"

6. Operation Modality:

Pharmacist opinion from zigatola, Panthapath. Information Like Name ,Sex, Religion ,Experience , Educational Qualification, Knowledge on computer or computer education Contact Number, Area of residence were analyzed by using Microsoft word and Microsoft Excel software, communication skills, how do counseling of the patient. 


\section{Data Collection Form}

1. Identification

1.1 License number:

1.2 Name:

1.3 Sex:

1.4 Religion:
1.5 Experience:

1.6 Educational qualification:

1.7 Knowledge on computer or computer education:

1.8 Contact number:

1.9 Address:

1.10 Serial No:

1.11 Date of Investigation:

2. Area of residence:

Rural $\square$ Urban $\square$ S-Urban $\square$ others $\square$

3. Without prescription did you provide any antibiotic or narcotic if he/she is your regular customers?

In favor

against

4. Do you maintain any design strategy for storage?

Yes

No

5. Which strategy you maintain?

Alphabet basis $\square$ Company name basis

6. Do you maintain any temperature?

Yes

No

7. What is the temperature do you maintain?

Below $30^{\circ} \mathrm{C} \square$ Normal temperature $\square$

8. Do you keep here any help line system?

Yes $\square$ No $\square$

9. There have any facilities on online delivery system?

Yes

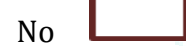

10. What type of facilities do you prefer here?

Discount system

$\square$ Membership card

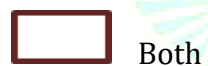

11. Do you keep here any room for patient counseling?

Yes $\square$ No

12. Do you like current drug distribution process?

Yes $\square$ No

13. If current drug distribution process establish digitalized would you accept it?

Yes

No

14. Do you think trend of pharmaceutical Marketing in Bangladesh is Digital or Analogue?

Digital $\square$ Analogue $\square$ Both

15. Do you think digital marketing will be helpful to overcome those problems of analog system?

Yes

No

No Opinion

16. If trend is Analogue then your opinion who is responsible for it?

Pharmaceutical company

Government

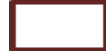

No Answer

17. If trend is digital then in your opinion what is the percentage of digital marketing use in pharmaceutical company in Bangladesh?

Less than $1 \%$

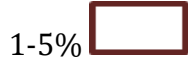

$5-10 \%$

More than $10 \%$

18. Digital Marketing System are of two types; Software-based and Network-based system. Which one do you like?

Software-based

Network-based

19. Some Bangladeshi pharmaceutical companies are using software-based digital marketing. If Pharmaceutical industries establish network-based system in digital drug marketing, will you support it?

Yes

No

No Comment

20. How much time you expect from the company to deliver you the drugs?

Less than 5 hours

5-8 hours

More than 8 hours

21. What type of benefit you expect if the total distribution system is digitalized?

Profits $\square$ Patients aid $\square$ No Comment $\square$ 


\section{Design of a Model Pharmacy}
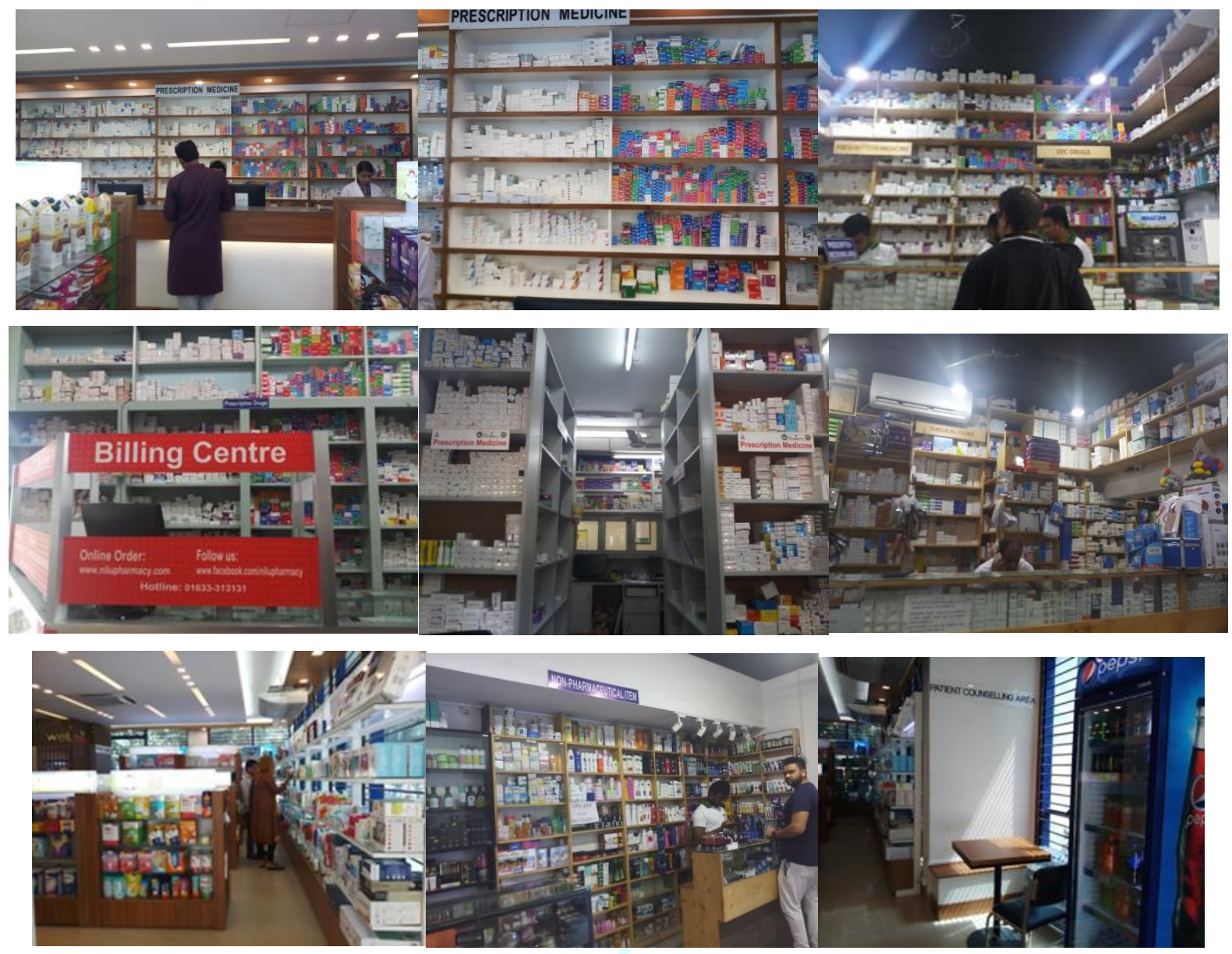

Figure 1: Design of a model pharmacy

This is the inside views of model pharmacy. Here kept medicated and non-medicated product separately. OTC medicine, prescription medicine, surgical item, counseling area and all's have been separated separately. Maintain the area is 300 square $\mathrm{ft}$.

\section{Result}

Table-1: Prevalence of design strategy for storage

\begin{tabular}{|l|l|l|}
\hline No of Pharmacy & Company Name basis & Alphabet Basis \\
\hline 20 & 20 & 0 \\
\hline
\end{tabular}

Table-1 showed that, out of 20 Pharmacies, $100 \%$ of them follow company name basis design strategy for storage.

Table 2: Using of helpline system

\begin{tabular}{|l|l|l|}
\hline No of Pharmacy & Yes & No \\
\hline 20 & 11 & 9 \\
\hline
\end{tabular}

Table-2 showed that, out of 20 Pharmacies, 65\% using helpline system and 45\% don't use helpline system.

Table-3: Facilities of online delivery system:

\begin{tabular}{|l|l|l|}
\hline No of Pharmacy & Yes & No \\
\hline 20 & 3 & 17 \\
\hline
\end{tabular}

Table-3 showed that, out of 20 Pharmacies, 25\% kept online order and delivery system and 75\% don't kept.

Table-4: Facilities on patient counseling area:

\begin{tabular}{|l|l|l|}
\hline No of Pharmacy & Yes & No \\
\hline 20 & 18 & 2 \\
\hline
\end{tabular}

Table-4 showed that, out of 20 Pharmacies, $80 \%$ kept patient counseling area and 20\% don't kept. The most important and significant factors that all's are counseling by 'A grade" Pharmacists. 


\section{Using software base/Network base/} Both

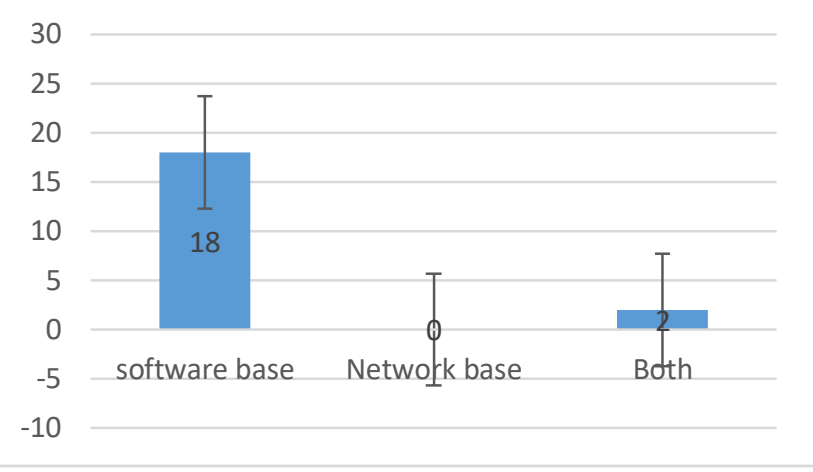

Figure 2: Using software base/Network base/ both

We found from figure 2 that, out of 20 Pharmacies, $80 \%$ of them used software tools and $20 \%$ used both software and network tools for their dispensing system.

\section{DISCUSSION:}

Model pharmacies are designed and organized in such a way that show the good dispensing practice, hygienic environment and display OTC and prescription medicines in separate places. Storage condition of the medicines at suitable temperature and provision of medical devices and healthcare services were noticed. Our study found that, out of 20 Pharmacies, $100 \%$ of them follow company name basis design strategy for storage. And they kept $80 \%$ facilities of patients counseling area, 65\% using helpline system and $45 \%$ don't use helpline system and $25 \%$ kept online order and delivery system and $75 \%$ don't kept. $80 \%$ of current model pharmacies are practicing software based tools for their dispensing of products. In the study find out that the Model pharmacy are gradually increases and some Model Pharmacy much improve, and there facilities, management system, drug distribution process and counseling system was very qualitative. Model Pharmacy prefers discount system and membership card both and it will be very acceptable for the patient.. Model pharmacy ensures safe \& effective medicine. For this reason it needs to be improved. Also these thing are need to be improved like counseling system, patient care management etc. The current situation of model pharmacy is good if it will be more improved then model pharmacy gradually increases and hopefully it will be very helpful for our country to digitalize. [13-22]

\section{Conclusion}

Pharmacy is the health profession that links the health sciences with the chemical sciences, and it is charged with ensuring the safe and effective use of medication. Pharmacy practice includes counseling and dispensing medications, and it also related to more modern services like patient care, including clinical services, reviewing medications for safety and efficacy, and providing drug information. Model pharmacy may be a suitable method to solve the health care related problems of Bangladesh. It is possible to ensure patients' safety and satisfaction by the expansion of model pharmacy and fulfilling the requirement of the criteria that influence patients to purchase medicines from model pharmacies rather than conventional retail pharmacies. It will be public private partnership. If the aim is successful, then it will be spread across Bangladesh and model pharmacy will be established gradually with digitalization.

\section{Acknowledgements}

The authors are thankful to the Department of Pharmacy, Daffodil International University for giving consent and all sort of supports to conduct the research.

\section{Conflict of Interest}

The authors declared that there is no conflict of interest.

\section{References}

1. https://www.slideshare.net/monnask/model-pharmacy-inbangladesh

2. http://alsew.org/life-science/model-pharmacy-a-new-erafor-health-in-bangladesh/

3. https://www.slideshare.net/HangHangOver/perspective-ofmodel-pharmacy-in-bangladesh

4. https://dgda.gov.bd/index.php/2013-03-31-05-1629/guidance-documents/175-guideline-for-model-pharmacy

5. www.sunamganj.gov.bd/...bd/.../2e2b41d4f054e6652a45bc3 30c9b9d64.docx

6. Casey MM, Moscovice IS, Davidson G. Pharmacist staffing technology use, and implementation of medication safety practices in rural hospitals. The Journal of Rural Health. 2006 Sep; 22(4):321-30.

7. https://www.slideshare.net/smnawed/guideline-for-modelpharmacy-in-bangladesh-level-1-75835650

8. https://bdnews24.com/health/2016/08/10/bangladesh-tointroduce-model-pharmacy-to-stop-fake-drug-sales

9. http://www.bpj-bd.com/index.php/currentissue/category/20-volume-21-no-1-january2018? download $=430$ :patients-perception-and-satisfactionon-model-pharmacies-in-dhaka-city-bangladesh.

10. Wafula, F.N., Miriti, E.M. and Goodman, C.A. 2012. Examining characteristics, knowledge and regulatory practices of specialized drug shops in Sub-Saharan Africa: a systematic review of the literature. BMC Health Serv. Res. 12, 223.

11. Woods, D.J. 1997. Extemporaneous formulations - problems and solutions. Pediatric Perinatal Drug. Ther. 1, 25-29.

12. Sultan, J. 2016. Future Prospects and Barriers of Pharmaceutical Industries in Bangladesh Pharm. J. 19, 53-57.

13. Nemchenko AS, Zhirova IV, Podgaynaya MV, Chernuha VN, Panfilova AL, Strelnikova YL. Principle of the organization of pharmacy.

14. Hopper T. Mosby's Pharmacy Technician-E-Book: Principles and Practice. Elsevier Health Sciences; 2014 Mar 14.

15. Fathelrahman A, Ibrahim M, Wertheimer A. Pharmacy practice in developing countries: achievements and challenges. Academic Press; 2016 Feb 13.

16. Downie G, Mackenzie J, Williams A, Milne C, Bedi R Pharmacology and Medicines Management for Nurses E-Book. Elsevier Health Sciences; 2007 Dec 28.

17. Bahadori M, Mohammadnejhad SM, Ravangard R, Teymourzadeh E. Using queuing theory and simulation model to optimize hospital pharmacy performance. Iranian Red Crescent Medical Journal. 2014 Mar; 16(3).

18. Hermansyah A, Sainsbury E, Krass I. Investigating influences on current community pharmacy practice at micro, meso, and macro levels. Research in Social and Administrative Pharmacy. 2017 Jul 1; 13(4):727-37.

19. Gilmer T, Kronick R, Fishman P, Ganiats TG. The medicaid R x model: pharmacy-based risk adjustment for public programs. Medical Care. 2001 Nov 1:1188-202.

20. Latif DA. Ethical cognition and selection-socialization in retail pharmacy. Journal of Business Ethics. 2000 Jun 1; 25(4):34357.

21. Krass I, Armour CL, Mitchell B, Brillant M, Dienaar R, Hughes J, Lau P, Peterson G, Stewart K, Taylor S, Wilkinson J. The Pharmacy Diabetes Care Program: assessment of a community pharmacy diabetes service model in Australia. Diabetic Medicine. 2007 Jun; 24(6):677-83.

22. Toklu HZ, Hussain A. The changing face of pharmacy practice and the need for a new model of pharmacy education. Journal of Young Pharmacists. 2013 Jun 1; 5(2):38-40. 